\title{
Benign Printing Paste from the Waste of Tamarind Seeds for Textile Printing. Part I: Basic Data
}

\author{
A. Hebeish'1, A.A. Ragheb ${ }^{1}$, I. Abdel-Thalouth' ${ }^{1}$, M. Adel Yousef ${ }^{2}$ and R.M. \\ Mahmoud \\ ${ }^{1}$ Textile Research Division, Pre-treatment and Finishing Of Cellulosic Fibers \\ Department, National Research Center (Scopus affiliation ID 60014618),33-El- \\ Behouth St. (former El-Tahrir St.), Dokki, P.O. 12622, Giza, Egypt \\ ${ }^{2}$ Faculty of Science, Helwan University, Cairo, Egypt.
}

$\mathbf{T}$ HICKENERS for textile printing were prepared from tamarind gum as per green technology; this tamarind gum is composed of glucose, xylose and galactose at a ratio of 3: $2: 1$ as isolated from tamarind seeds. In order to render the tamarind seeds soluble in water, they were submitted to chemical modification by carbamation followed by miniaturization through sonication.

The as prepared biopolymer was used as a thickener for textile printing of a natural dye colorant was extracted from the tamarind seed cover (coat) after being manually which separated from the seed.

To this end, we have the biopolymer ready for use as a thickener and the extracted colorant ready for use as natural dye. Addition of the two components to the printing mix would give rise to benign printing paste which could be successfully used in printing on various textile materials notably cotton, natural silk and wool after being mordanted. Nitrogen content, rheological properties, color strength and overall color fastness properties were evaluated.

Keywords: Green technology, Tamarind seed gum, Innovative thickener, Natural dye, Nanotechnology.

\section{Introduction}

Tamarind seed gum, known also as tamarind karnel powder (TKP), is extracted from the seed of Tamarindus indica linn. [1]. It belongs to the dicotylendonous subfamily Caesalpinioideae (Leguminosae) [2].

Tamarind seed gum, a crude extract of tamarind seeds, is rich in polysaccharide $(\sim 65$ $72 \%$ ) [3], which contains glucose, xylose and galactose units, in a molecular ratio of $\sim 3: 2: 1$ [4$6]$. The structure of tamarind seed gum is based on a B(1----4)_D_glucan backbone, substituted at position 6 of glucopyranosyl units mainly by single $\alpha$-D-Xylopyranosyl residues [5]. In addition, tamarind seed gum is a high molecular weight polysaccharide [4,6-7], forms viscous solution upon dissolution in water as many polysaccharide gums extracted from plant materials. Presently, tamarind seed gum has potential for commercial applications in several disciplines such as pharmaceutical and textile industries [8-10].

Urea is, on the other hand, one of the most important materials used in the fields of textile finishing and printing. During printing, urea acts as a solvent for the dye meanwhile it promotes the dye migration from the printed film to the fiber interior.

Current work is undertaken with a view to harness tamarind seeds waste as a new and renewable resource for preparation of new polysaccharide biopolymer and natural colorant. While the biopolymer is isolated as tamarind gum the natural colorant dye is extracted from the tamarind seed cover (coat) after being manually separated from the seeds. By virtue of its insolubility in water, the biopolymer was submitted to derivatization via carbamation followed by sonication in order to make it water soluble. To this end, the biopolymer is used as a thickener and colorant as natural dye giving

*Corresponding author e-mail: reham_egypt_blood@yahoo.com 
together rise to benign printing paste. Thus innovated printing paste is used in printing of various textile materials, notably cotton, natural silk and wool after being mordanted. The innovation is based on investigation pertaining to miniaturization of the gum before and after carbamation via sonication. Nitrogen content, rheological properties, colour strength and overall fastness properties of the printed fabrics are measured. In this research we describe preparation of the new polysaccharide based gum, its derivatization and the onset of sonication and carbamation on particle size, water solubility and rheological properties of the new products so obtained, Early reports [11] disclosed that urea reacts with alcohol and polyhydric alcohols to bring about the corresponding carbamated derivatives. Furthermore, it has been shown that urea decomposes at high temperature with the loss of ammonia to form cyanic acid. The latter reacts with alcohol to yield carbamates [12].

\section{Experimental}

\section{Materials}

Cotton fabric

Mill desized, kier boiled and bleached poplin cotton $\left(140 \mathrm{~g} / \mathrm{m}^{2}\right)$, produced by Misr/Helwan for Spinning and Weaving Company, was used throughout the present work.

Natural silk fabric

Mill scoured natural silk $\left(81 \mathrm{~g} / \mathrm{m}^{2}\right)$ fabric supplied by Hussien El-Khatib sons company Suhag, upper Egypt, was also used.

\section{Wool fabric}

Mill scoured 100\% wool fabric (270 g/ m2) supplied by Misr Company for Spinning and Weaving, Mehalla El Kubra, Egypt, was additionally used.

\section{Plant seeds}

Dry and clean tamarind seeds were obtained from local fresh drinking shop. They are the remaining residual waste of tamarind juice. The seeds are composed of three components, namely, hull, endosperm, and germ, all were and obtained from ripe pods [13].

\section{Mordants}

Tannic acid, ferrous sulphate and allum were used as mordants for fixing the tamarind natural colour.

\section{Other chemicals}

Calcium chloride and urea were of laboratory grade chemicals, whereas ethyl alcohol (75\%) was of commercial grade.

\section{Methods}

Separation of the gum from the seeds

The gum was isolated from the seeds according to a reported method as follows: The tamarind seeds were dried in an oven at $100^{\circ} \mathrm{C}$ for $30 \mathrm{~min}$. and the seed coat was manually removed from the seeds. Then, the coatless seeds (i.e. gum) were grinded through ball milling and sieved using 355 nm mesh sieve.

\section{Preparation of tamarind gum carbamate}

The above obtained tamarind gum was mixed with urea at ratio of 5:1 in a mechanical mixer. The mixture was subjected to thermal treatment at $165^{\circ} \mathrm{C}$ for different periods of time $(60,90$, and 120 min.) A blank sample was prepared by submitting the gum to thermal treatment at the same temperature for $120 \mathrm{~min}$., this so treated sample will be referred to as the control sample.

Purification of the carbamate derivatives of tamarind

The aforementioned tamarind gum carbamate prepared as described above were purified by soxlet extraction using commercial ethanol (75\%) till free from the unreacted urea and the so purified products were dried in a discicator containing dry calcium chloride.

\section{Sonication}

The prepared tamarind carbamate gum along with the control sample were sonicated using ultrasonic stirrer (SONICS \& MATERIALS). Sonication was carried out as follows: $5 \mathrm{gm}$ of the gum were suspended in $100 \mathrm{ml}$ water. Thus obtained suspension was sonicated for 30 min. at ca $80^{\circ} \mathrm{C}$, Particle size using TEM along with rheological properties of the miniaturized tamarind (Sonicated) carbamate gum were monitored.

\section{Preparation of natural dye}

The natural dye was prepared from external cover (coat) of the seed of tamarind as per the following steps:

Tamarind seeds were dried and their external cover was manually removed as outlined above. Material represented by the isolated external cover (coat) of the tamarind seeds were submitted to soxlet extraction using commercial ethanol 
(75\%).The extract containing the colour (dye) was concentrated by using (rota-vapour system) at $50^{\circ} \mathrm{C}$, giving rise to highly concentrated extract.Thus obtained concentrated extract was left to dry under ambient conditions, leading to coloured materials. The coloured materials exhibited crystals form with shiny appearance. These crystals were used as a natural dye in current work.

\section{Analysis and measurements}

Determination of nitrogen content

The nitrogen content of the purified tamarind gum carbamate derivatives was determined at Micro Analytical Laboratory, NRC, Egypt.

Determination of rheological properties [14]

The rheological properties of tamarind gum carbamate derivatives pastes "of concentration 5\%" were measured using PROGRAMABLE RHEOMETER $[15,16]$.

\section{TEM [18]}

Particle shape and size were obtained using a JEOLJEM 1200. Specimens for TEM measurements were prepared by dissolving a drop of colloid solution on a 400 mesh copper grid coated by an amorphous carbon film and evaporating the solvent in air at room temperature. The average diameter of the pigment nanoparticles was determined from the diameter of 100 nanoparticles found in several arbitrarities chosen areas in enlarged microphotographs.

\section{Result and Discussion}

Gum isolated from tamarind seeds was found to be sparingly soluble in water. This stimulates our interest to make it water-soluble. To achieve the goal, two approaches are studied either individually or in combination. The first approach involves sonication of the gum in order to reduce its particle size.

The second approach is based on derivatization of the gum via carbamation. The latter is performed by reacting the gum with urea using the solid state technique.

\section{Sonication of the gum}

The tamarind gum $5 \mathrm{~g} / 100 \mathrm{ml}$ water was subjected to sonication for $30 \mathrm{~min}$. Particle size of the gum was measured before and after sonication

TABLE 1. particle sizes of the tamarind gum before and after sonication.

\begin{tabular}{lcc}
\hline Nature of gum & \multicolumn{2}{c}{ Size of particle } \\
& Before sonication & After sonication \\
\hline Pure gum "\%N: Zero" & $347 \mathrm{~nm}$ & $70 \mathrm{~nm}$ \\
\hline
\end{tabular}

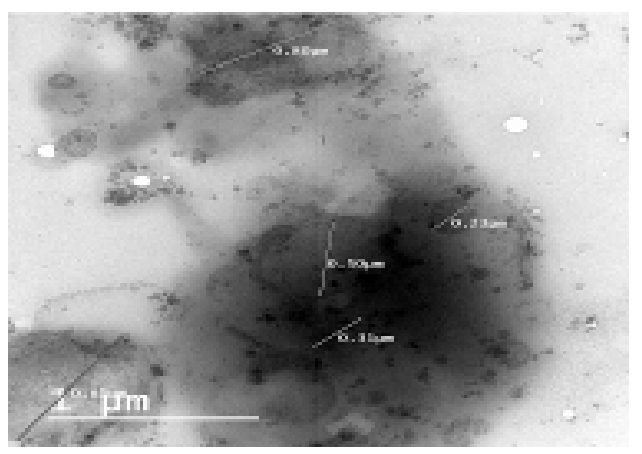

Fig. 1. TEM micrograph of Tamarind gum prepared using the gum at a concentration of $5 \mathrm{gm} / 100 \mathrm{ml}$ water before sonication.

by making use of TEM microscopy. On the other hand, rheological properties, specifically, the apparent viscosity was measured at different rates of shear. Figures 1 and 2 show the TEM images of tamarind gum before and after sonication respectively. It is clear that the particle size of the native gum acquires a value of $347 \mathrm{~nm}$ before
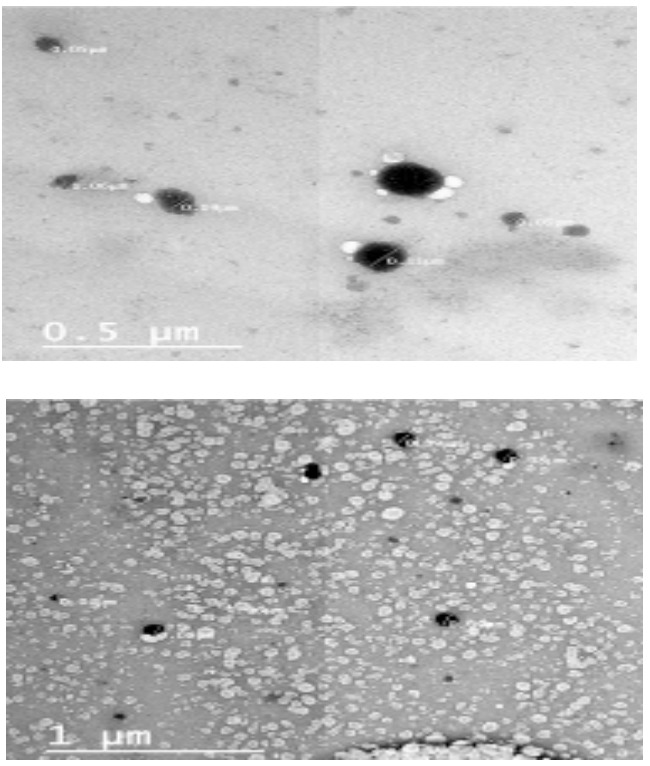

Fig. 2. TEM micrograph of Tamarind gum prepared using the gum at a concentration of $5 \mathrm{gm} / 100 \mathrm{ml}$ water after sonication for $30 \mathrm{~min}$. at $80^{\circ} \mathrm{C}$

Egypt.J.Chem. Special Issue (2017) 
sonication. This is against a value of $70 \mathrm{~nm}$ for the particle size after sonication. That is the value of the particle size decreases dramatically by sonication from $347 \mathrm{~nm}$ to $70 \mathrm{~nm}$ as represented in Table 1 .

Figure 3 (of Table 2) demonstrates the apparent viscosity of tamarind gum at a concentration of $5 \%$ before and after sonication when the apparent viscosity was measured at different rates of shear. The results signify two important features. First, the apparent viscosity of the gum decreases dramatically before and after sonication by increasing the rate of shear.

Second, the apparent viscosity decreases outstandingly by increasing the rate of shear, a finding obtained before sonication. Nevertheless, the values of apparent viscosity at all rates of shear within the range studied are much greater after than before sonication. For instance at a rate of shear of ca. $17 \mathrm{sec}^{-1}$, the gum displays viscosity values of 528 and ca. 970 centipoises before and after sonication respectively. Similarly, at a rate of shear of ca. $25 \mathrm{~cm}^{-1}$, the apparent viscosity exhibits values of 70 centipoises and ca. 516 centipoises before and after sonication respectively. To this end, results of Table 2 and Fig. 3 make it evident that the effect of the rate of shear in decreasing the apparent viscosity of the tamarind gum is

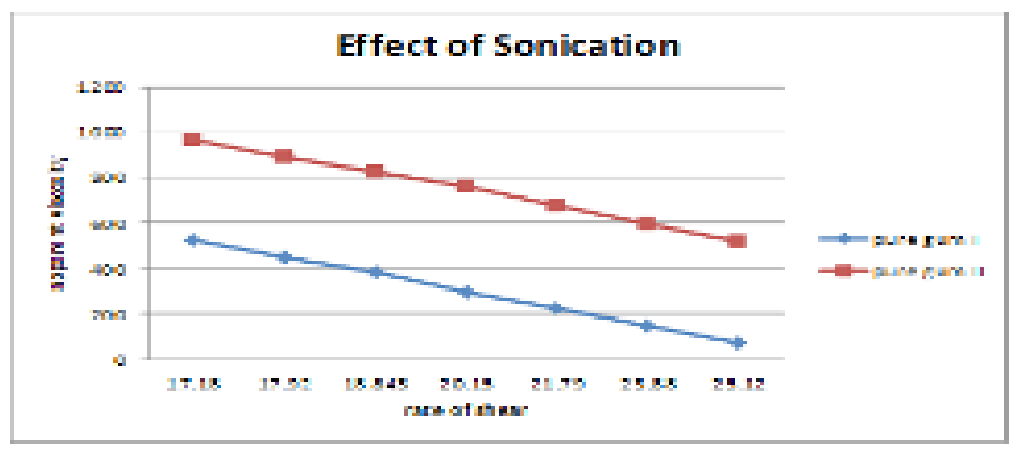

Fig. 3. Apparent viscosity of tamarind gum before and after sonication at different rates of shear.

TABLE 2. Effect of sonication of tamarind pure gum on the apparent viscosity at different rates of shear.

\begin{tabular}{ccc}
\hline $\begin{array}{c}\text { Rate of shear } \\
\text { Sec }^{-1}\end{array}$ & \multicolumn{2}{c}{ Apparent viscosity in centipoise for tamarind gum } \\
& $\mathrm{I}$ & $\mathrm{II}$ \\
\hline 17.18 & 528.0 & 970.5 \\
17.920 & 450.6 & 893.3 \\
18.843 & 382.6 & 826.5 \\
20.150 & 294.6 & 759.2 \\
21.790 & 225.6 & 676.8 \\
23.880 & 147.6 & 593.4 \\
25.12 & 70.1 & 516.5 \\
\hline
\end{tabular}

- I $\rightarrow$ before sonication

II $\rightarrow$ after sonication.

much more pronounced with the unsonicated than the sonicated tamarind gum. Sonication not only increases the apparent viscosity but also, increases resistance of the viscous solution of the sonicated gum to flow.

With the above in mind it is logical to assume that sonication causes disintegration and miniaturization of tamarind gum leading to nanosized gum particles. Indeed the particle size of the

Egypt.J.Chem. Special Issue (2017) gum decreases from 347 to $70 \mathrm{~nm}$ (cf Table 1), by sonication. Beside such dramatic decrease which converts the gum particle to the nano-size scale, sonication seems to function in favour of forming more ordered gum particles and allow these particles to take part in the formation of the gum solution. Once this is the case, the apparent viscosity will increase, a point which explains the significant increase in viscosity and lower response of the viscous solution to higher rates of shear. 
Chemical modification of tamarind gum via carbamation

After being dried the tamarind gum under investigation was reacted with urea as per the solid state technique [19]. The reaction was conducted at $165^{\circ} \mathrm{C}$ for different durations, namely 60,90 , and $120 \mathrm{~min}$. as detailed in the experimental section. Reaction of the gum with urea may generally be represented as follow:

Gum-OH $+\mathrm{H}_{2} \mathrm{~N}-\mathrm{CO}-\mathrm{NH}_{2}-----\mathrm{Gum}-\mathrm{O}-\mathrm{CO}-$
$\mathrm{NH}_{2}+\mathrm{NH}_{3}$

Previous reports [20] have also disclosed that urea decomposes at high temperature and looses ammonia to form cyanic acid $(\mathrm{HN}=\mathrm{C}=\mathrm{O})$ which react with hydroxyl groups of the carbohydrate to give the carbamate derivative, thus:

$$
\text { Gum-OH+NH=C=O-------Gum-O-CO-NH }
$$

After the necessary purification, the obtained carbamate derivative of tamarind gum was

TABLE 3. Effect of time of reaction on the extent of carbamation, expressed as \% $\mathbf{N}$.

\begin{tabular}{ccc}
\hline Time of reaction $(\mathbf{m i n})$ & $\mathbf{\%} \mathbf{N}$ & Solubility in water \\
\hline 0 & 0 & Swelled Only \\
60 & 3.96 & Partially Soluble \\
90 & 4.65 & Partially Soluble \\
120 & 5.14 & Partially Soluble \\
\hline
\end{tabular}

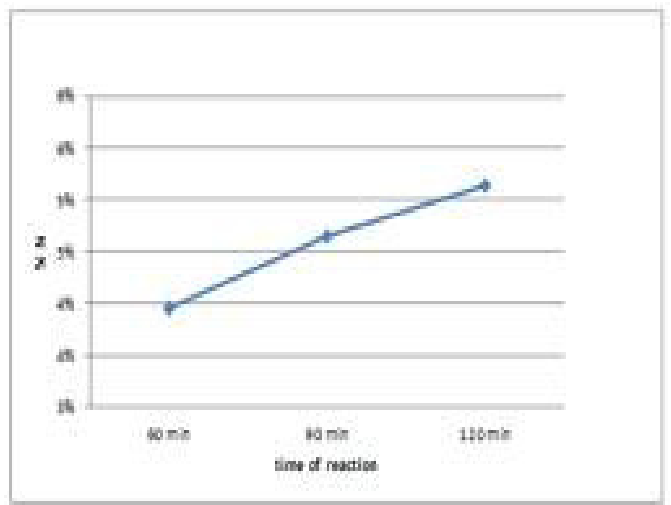

Fig. 4. Dependence of the extent of carbamation, expressed as $\% \mathrm{~N}$ on reaction time.

analyzed for nitrogen which was taken as measure of the extent of carbamation.

The results obtained are given in Table 3 and Fig. 4.

The carbamation reaction was carried out at $165^{\circ} \mathrm{C}$ using gum: urea ratio of $5: 1$

Variations of the extent of carbamation of the gum with reaction time are shown in Table 3 and Fig. 4. As is evident the extent of carbamation enhances substantially by increasing the duration of carbamation from 60 to $120 \mathrm{~min}$. which is, indeed the range studied. This could be ascribed to the impact of duration in providing a longer time of contact among reactants for carbamation to proceed. When urea was allowed to react with the gum for 60 min., a nitrogen content of 3.96\% could be achieved. This is against a value of nitrogen content of $5.14 \%$ when urea was allowed to react with the gum for $120 \mathrm{~min}$.

Rheology of thermally treated gum vis-à-vis untreated gum

A control sample was prepared by submitting the tamarind gum sample to thermal treatment at $165^{\circ} \mathrm{C}$ for $120 \mathrm{~min}$. This is rather the condition of carbamation of the gum but in absence of urea. Apparent viscosity of the so obtained thermally treated gum (control) was measured at different rates of shear and compared with those obtained tamarind gum are shown in Fig. 5 and set out in Table 4. A gum viscous solution of $5 \%$ concentration was used to measure the rheological properties of the control as well as the untreated gum.

Results of Table 4 show that the apparent viscosity of the thermally treated gum sample (control) decreases appreciably by increasing the rate of shear. Similar situation is encountered with the untreated gum. However, the decressents in apparent viscosity are much lower in case of control sample than those of the tamarind gum as shown in Table 4 and Fig. 5. Indication of this is that the gum undergoes thermal degradation which gives rise to larger number of polymer chains with lower molecular weight. In combination with this is increased solubility along with the highly swollen particles in the entire gum solution. The ultimate effect of this would be reflected on the measured viscosity.

Decreases of the apparent viscosity by increasing the rate of shear indicate that these pastes are characterized by a non-neutonian 
TABLE 4. Apparent viscosity of tamarind gum vis-a-vis thermally treated gum at different rates of shear.

\begin{tabular}{ccc}
\hline \multirow{2}{*}{ Rate of shear "sec-1" } & \multicolumn{2}{c}{ Apparent viscosity (centipoise) } \\
& Tamarind gum & Thermally treated gum \\
\hline 17.18 & 528.0 & 853.2 \\
17.920 & 450.6 & 785.1 \\
18.843 & 382.6 & 715.6 \\
20.150 & 294.6 & 638.6 \\
21.790 & 225.6 & 550.6 \\
23.880 & 147.6 & 475.7 \\
25.12 & 70.1 & 386.7 \\
\hline
\end{tabular}

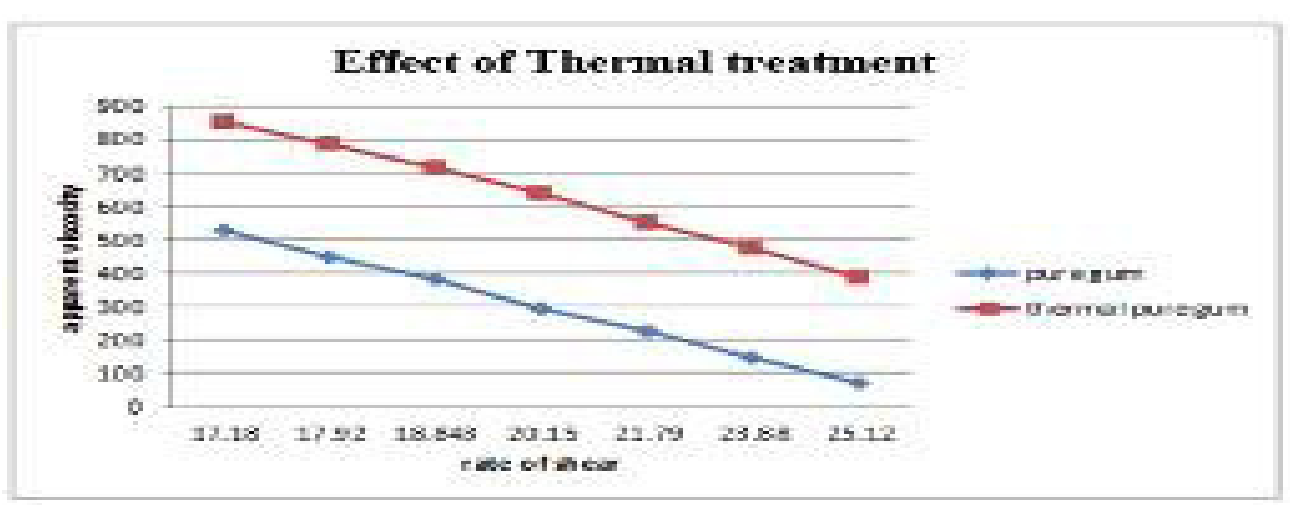

Fig. 5. Apparent viscosities of tamarind gum before and after thermal treatment plotted against rates of shear.

pseudo plastic behavior.

SEM of Carbamated gum and thermally treated gum before and after sonication

The carbamated gum along with its thermally treated gum control at a concentration of $5 \%$ were sonicated as previously described. The particle size of the carbamated and control samples was measured by making use of SEM and images obtained are shown in Fig. 6-13. The carbamated samples under examination acquire $\mathrm{N} \%$ values of 3.96, 4.65, and 5.14\%. SEM images in Fig. 6, $7,8,9,10$ and 11 display that the particle size decreases after sonication from $260 \mathrm{~nm}$ to $43 \mathrm{~nm}$, from $254 \mathrm{~nm}$ to $38 \mathrm{~nm}$, from $230 \mathrm{~nm}$ to $29 \mathrm{~nm}$, for carbamated sample having 3.96, 4.65 and $5.14 \% \mathrm{~N}$ respect to thermally treated gum control. Figures 12 and 13 show that the particle size decreases after sonication from $287 \mathrm{~nm}$ to $58 \mathrm{~nm}$.

Based on the foregoing, carbamation decreases the particle size of tamarind gum and this decrement is lower at higher extent of carbamation (high \% N). Sonication reduces dramatically the particle size of the carbamated gum irrespective of the $\% \mathrm{~N}$.

The control sample exposed to condition identical to those of carbamation but in absence of urea displays also a dramatic reduction in the particle size, the latter decreases from 237 to 58 nm after sonication.

Different situation is encountered after sonication where the particle sizes of the carbamated samples are larger than that of the control sample. This reflects nature of the gum and its onset on the behavior of the gum towards ultrasound radiation.

Rheological properties of the carbamated gum derivatives

The apparent viscosity of carbamated gum derivatives is measured after sonication and compared with the results of apparent viscosity of these same three samples as shown in Table 5 and Fig. 14. It is seen that for a given rate of shear, the apparent viscosity of the carbamated gum increases by increasing the nitrogen content of the latter. It is also seen that the nitrogen content is a manifestation of carbamation time because the extent of carbamation expressed as $\% \mathrm{~N}$ increases by increasing the duration of carbamation from 60 up to $120 \mathrm{~min}$. On the other hand, the apparent 

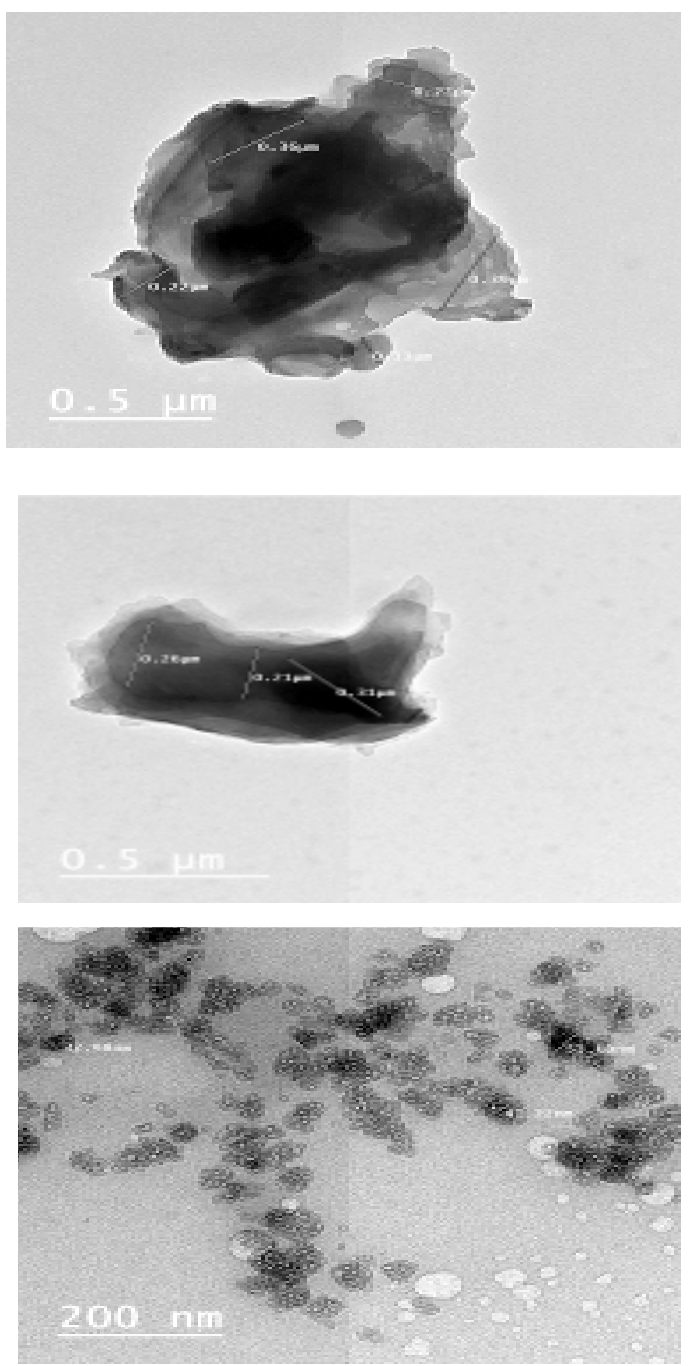

Fig. 6. TEM micrograph of tamarind Carbamated gum using gum: urea ratio $5: 1$ at $165^{\circ} \mathrm{C}$ for $30 \mathrm{~min}$ before sonication at $\% \mathrm{~N} 3.96$.

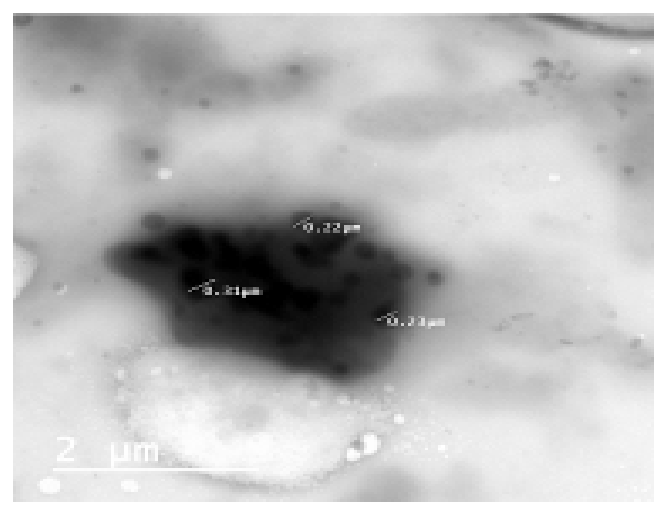

Fig. 7. TEM micrograph of Tamarind Carbamated gum using gum: urea $5: 1$ at $165^{\circ} \mathrm{C}$ for 60 min before Sonication at $\% \mathrm{~N} 4.65$.

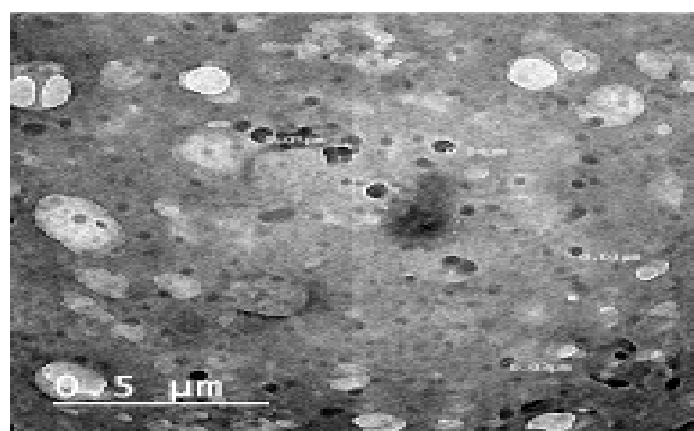

Fig. 8. TEM micrograph of Tamarind Carbamated gum using gum: urea $5: 1$ at $165^{\circ} \mathrm{C}$ for 60 min after Sonication at $\% \mathrm{~N} 4.65$.

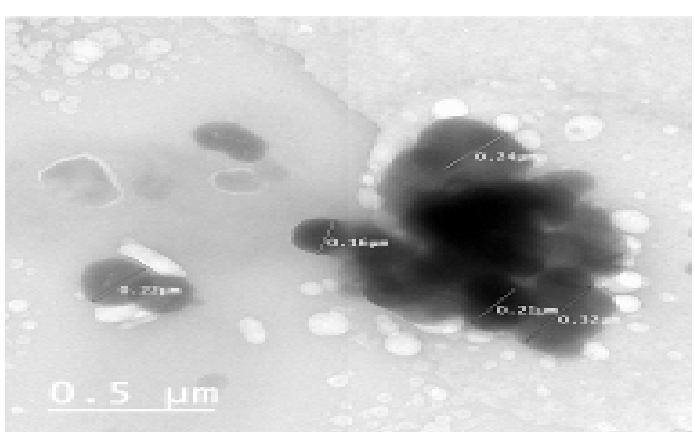

Fig. 9. TEM micrograph of Tamarind Carbamated gum using gum: urea $5: 1$ at $165^{\circ} \mathrm{C}$ for 120 min before Sonication at \%N 5.14 .
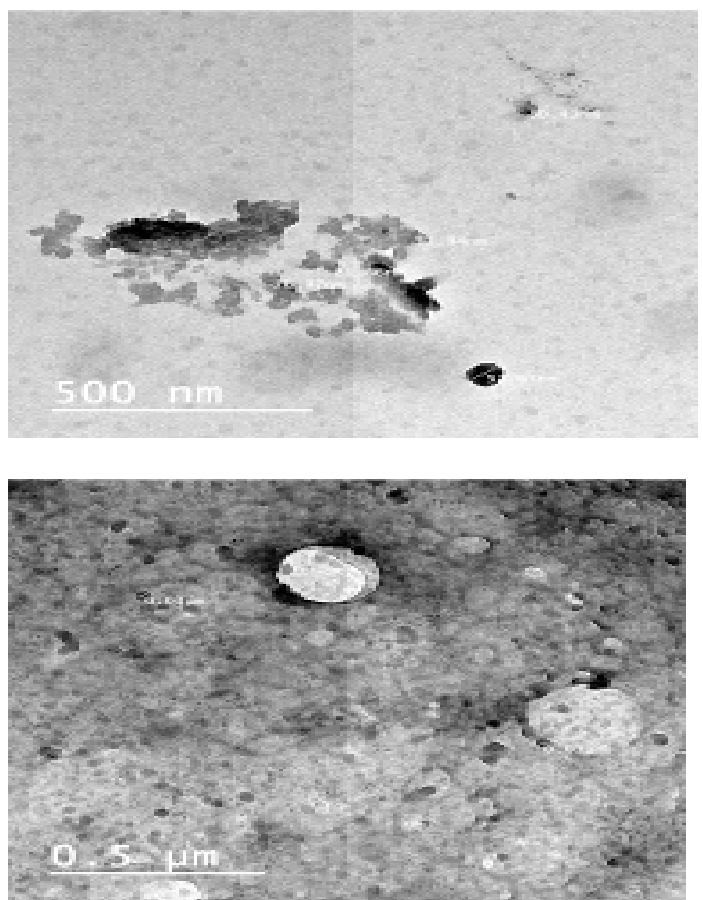

Fig. 10. TEM micrograph of Tamarind Carbamated gum using gum: urea 5:1 at $165^{\circ} \mathrm{C}$ for 120 min after Sonication at \%N 5.14. 


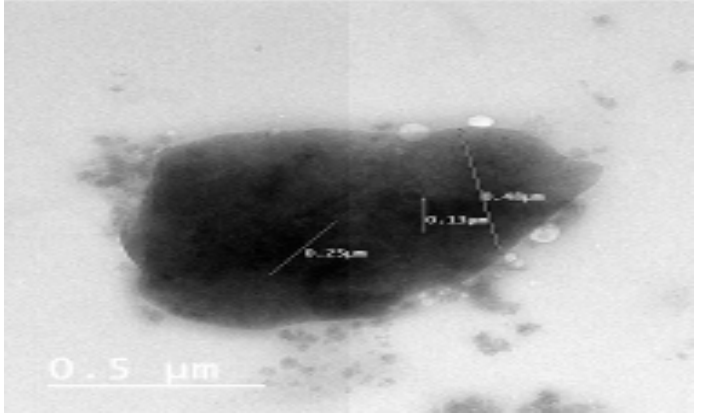

Fig. 11. TEM micrograph of thermally treated tamarind pure gum using gum at a concentration of $5 \mathrm{gm} / 100 \mathrm{ml} \mathrm{H} 2 \mathrm{O}$ at $165^{\circ} \mathrm{C}$ for $120 \mathrm{~min}$ before sonication
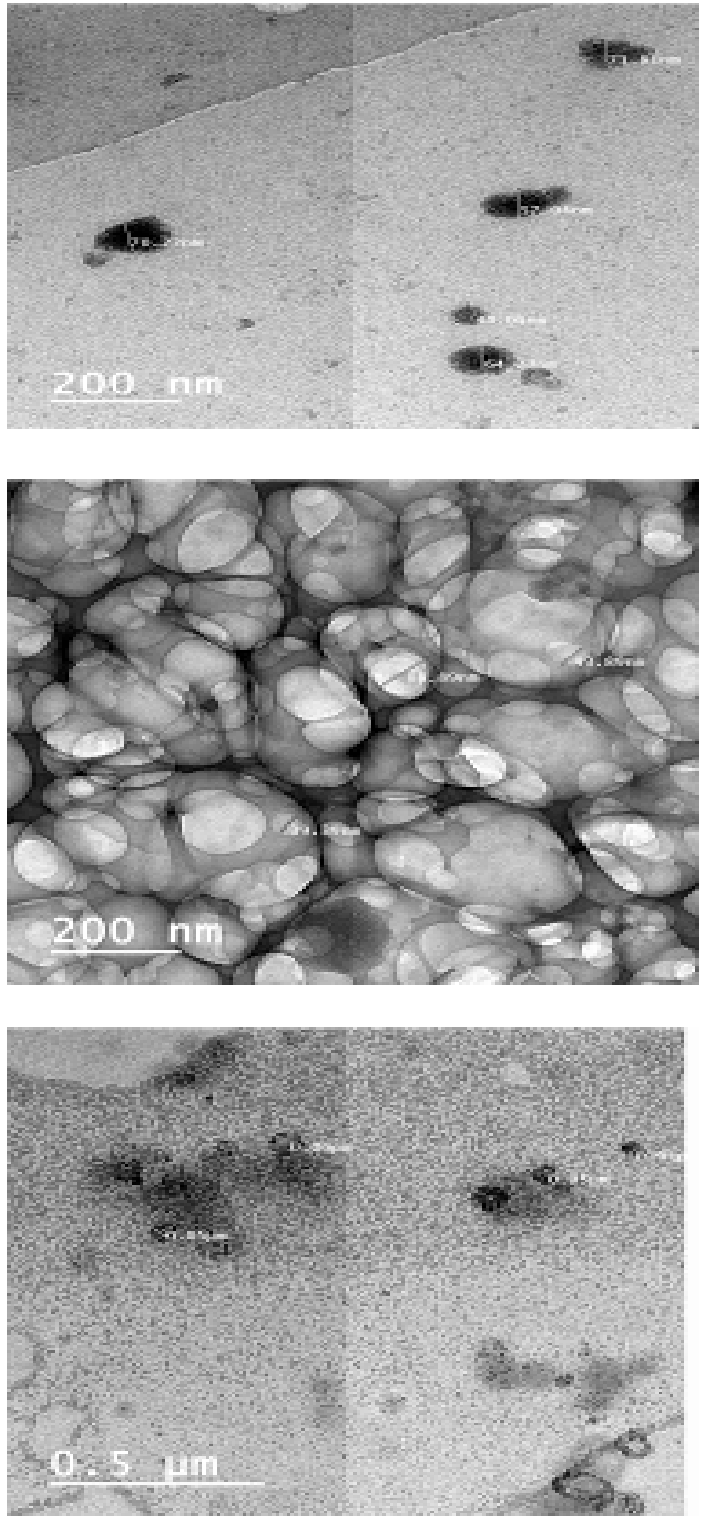

Fig. 12. TEM micrograph of thermally treated tamarind pure gum using gum at a concentration of $5 \mathrm{gm} / 100 \mathrm{ml} \mathrm{H}_{2} \mathrm{O}$ at $165^{\circ} \mathrm{C}$ for $120 \mathrm{~min}$ after sonication

Egypt.J.Chem. Special Issue (2017)

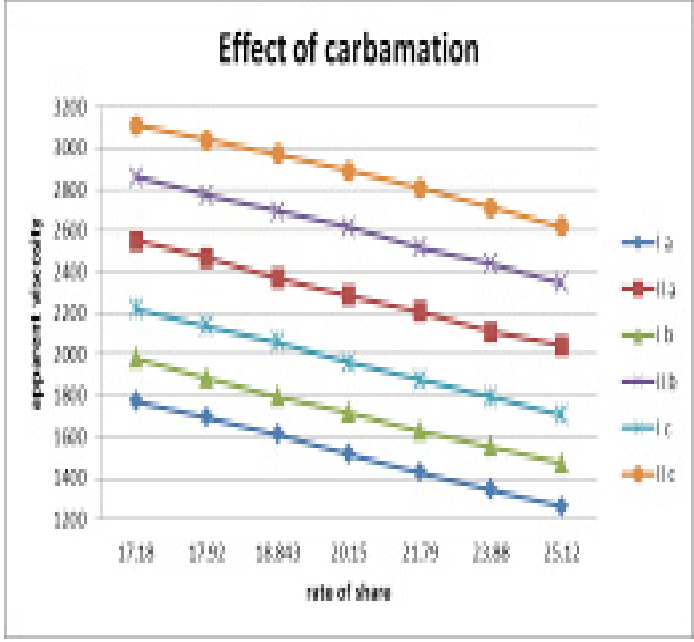

Fig. 13.

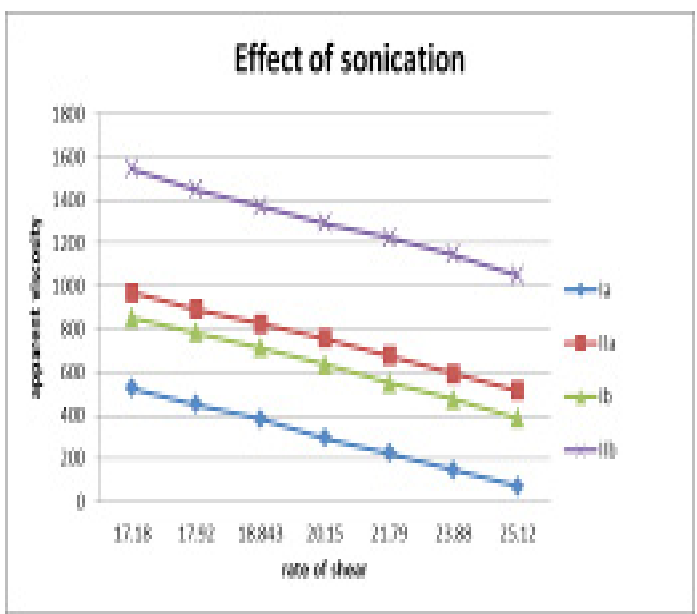

Fig. 14.

viscosity decreases as the rate of shear increases due to fast mechanical action which decreases molecular collision in the viscous solution under test.

The effect of miniaturization by sonication of carbamated gum sample is to enhance significantly the apparent viscosity of these samples. Sonication seems to augument solubility and/or disintegration of the carbamated gum and, in so doing, solicit more participation of entities of the viscosous solution in molecular association (aggregation) thereby increasing its resistance to flow.

Table 5 makes it evident that the apparent viscosity decreases from 1773.1 to 1262.5 centipoise for the sample having $3.96 \mathrm{~N} \%$ before sonication. The same sample decreases from the 2553 to 2043.8 centipoise after sonication 
at different rates of shear ranging from 17.18 to 25.12 sec- 1 .

And the apparent viscosity of the carbamated sample having $4.65 \% \mathrm{~N}$ decreases from 1981.5 to 1472.5 centipoise before sonication and from 2861.5 to 2346.3 after sonication. The rate of shear ranged from 17.18 to 25.12 sec- 1 .

And the apparent viscosity of \% N 5.14 decrease from 222.18 to 1706.2 centipoise before sonication and from 3111.8 to 2619.3 after sonication by increasing the rate of shear from 17.18 to 25.12 sec- 1 .

Thus the apparent viscosity increases from 1515.8 to 1719.8 to 1962.3 centipoise for carbamated samples which acquire 3.96, 4.65,
$5.14 \% \mathrm{~N}$ before sonication at rate of shear 20.10 "sec-1".

And the apparent viscosity increases from 2285.6 to 2616.9 to 2892.5 centipoise for these carbamated gum of $3.96 \% \mathrm{~N}, 4.65 \% \mathrm{~N}$, and $5014 \% \mathrm{~N}$ respectively after sonication . A rate of shear of 20.150 (sec-1) was employed.

Furthermore, variations of apparent viscosity by sonication of native and thermally treated gum are clearly shown in Table 6 and Fig. 15.

Before sonication the apparent viscosity increases from 225.6 to 550.6 centipoise with respect to the native and thermally treated gum respectively at rate of shear $21.790 \mathrm{sec}-1$. And the apparent viscosity also increase from 676.8 to

TABLE 5. Effect of carbamation of tamarind seeds gum on the apparent viscosity at different rates of share.

\begin{tabular}{|c|c|c|c|c|c|c|}
\hline \multirow{3}{*}{ Rate of shaer $\left(\sec ^{-1}\right)$} & \multicolumn{6}{|c|}{ Apparent viscosity in centipoise for carbamate gum acquires } \\
\hline & \multicolumn{2}{|c|}{$3.96 \% \mathrm{~N}$} & \multicolumn{2}{|c|}{$4.65 \% \mathrm{~N}$} & \multicolumn{2}{|c|}{$5.14 \% \mathrm{~N}$} \\
\hline & I a & II a & $\mathbf{I} \mathbf{b}$ & II b & I c & II c \\
\hline 17.18 & 1773.1 & 2553 & 1981.5 & 2861.5 & 2221.8 & 3111.8 \\
\hline 17.920 & 1694.8 & 2468.4 & 1885.1 & 2772.1 & 2137.9 & 3042 \\
\hline 18.843 & 1610.8 & 2371.2 & 1797.7 & 2694.7 & 2058.7 & 2972.3 \\
\hline 20.150 & 1515.8 & 2285.6 & 1719.8 & 2616.9 & 1962.3 & 2892.5 \\
\hline 21.790 & 1426.7 & 2207.8 & 1631 & 2517.8 & 1877.5 & 208.6 \\
\hline 23.880 & 1342.3 & 2111.7 & 1552.4 & 2440.5 & 1792.6 & 2713.8 \\
\hline 25.12 & 1262.5 & 2043.8 & 1472.5 & 2346.3 & 1706.2 & 2619.3 \\
\hline
\end{tabular}

I a $\rightarrow$ a sample prepared at $165^{\circ} \mathrm{C}$ for 1 hour

$\mathrm{I} \mathrm{b} \rightarrow$ a sample prepared at $165^{\circ} \mathrm{C}$ for $\mathrm{z}$, hour

I c $\rightarrow$ a sample prepared at $165^{\circ} \mathrm{C}$ for 2 hour

II a $\rightarrow$ I a after miniaturization

II $b \rightarrow$ I b after miniaturization

II $\mathrm{c} \rightarrow$ I c after miniaturization

TABLE 6. The effect of sonication on the apparent viscosity of native gum and thermally treated gum.

\begin{tabular}{|c|c|c|c|c|}
\hline \multirow{3}{*}{$\begin{array}{l}\text { Rate of shear } \\
\qquad\left(\sec ^{-1}\right)\end{array}$} & \multicolumn{4}{|c|}{ Apparent viscosity in centipoise for } \\
\hline & \multicolumn{2}{|c|}{ Pure gum (native) } & \multicolumn{2}{|c|}{ Thermally treated pure gum at $165^{\circ} \mathrm{C}$ for $2 \mathrm{hr}$} \\
\hline & Ia & IIa & Ib & IIb \\
\hline 17.18 & 528.0 & 970.5 & 853.2 & 1545 \\
\hline 17.920 & 450.6 & 893.3 & 785.1 & 1449.3 \\
\hline 18.843 & 382.6 & 826.5 & 715.6 & 1371.3 \\
\hline 20.150 & 294.6 & 759.2 & 638.6 & 1292.4 \\
\hline 21.790 & 225.6 & 676.8 & 550.6 & 1225.6 \\
\hline 23.880 & 147.6 & 593.4 & 475.7 & 1147.2 \\
\hline 25.12 & 70.1 & 516.5 & 386.7 & 1049.9 \\
\hline $\begin{array}{ll}\text { - } & \text { Ia } \rightarrow \text { Pure g } \\
\text { - } & \text { IIa } \rightarrow \text { Pure g } \\
\text { - } & \text { Ib } \rightarrow \text { Therm } \\
\text { - } & \text { IIb } \rightarrow \text { therm }\end{array}$ & $\begin{array}{l}\text { ication } \\
\text { ication } \\
\text { um befor } \\
\text { um after }\end{array}$ & & & \\
\hline
\end{tabular}




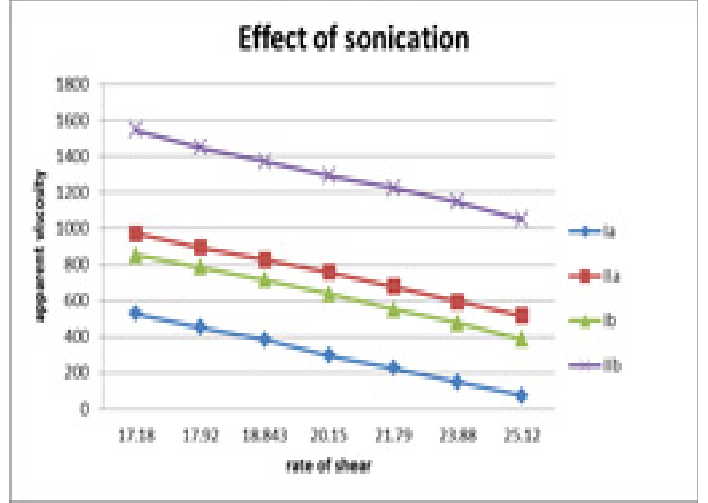

Fig.15
1225.6 centipoise of the pure gum and thermally treated gum respectively at rate of shear 21.790 sec-1 after sonication .

Table 7 effect of sonication on the particle size of thermally treated control sample and carbamated gum derivatives.i.e. Different extents of carbamated samples, were sonicated for $30 \mathrm{~min}$. at $80^{\circ} \mathrm{C}$. The control sample, i.e. gum thermally treated at $165^{\circ} \mathrm{C}$ for $120 \mathrm{~min}$. was similarly sonicated. Particle size of the gum derivatives, and the control sample before and after sonication are set out in Table 7 .

First perusal at the results of Table 7 would

TABLE 7. Effect of sonication on the variation of particle size of thermally treated control sample and carbamated gum drivatives.

\begin{tabular}{ccc}
\hline Nature of the gum & \multicolumn{2}{c}{ Size of particle } \\
& Before sonication & After sonication \\
\hline Thermally treated gum "\% N: Zero" & $287 \mathrm{~nm}$ & $58 \mathrm{~nm}$ \\
$3.96 \% \mathrm{~N}$ & $260 \mathrm{~nm}$ & $43 \mathrm{~nm}$ \\
$4.65 \% \mathrm{~N}$ & $254 \mathrm{~nm}$ & $38 \mathrm{~nm}$ \\
$5.14 \% \mathrm{~N}$ & $230 \mathrm{~nm}$ & $29 \mathrm{~nm}$ \\
\hline
\end{tabular}

reveal that sonication under the condition used converts the particles of the tamarind gum to the Nano-scale particles (less than $100 \mathrm{~nm}$ ) irrespective of the extent of carbamation. However, the control sample exhibits particle sizes of $287 \mathrm{~nm}$ and 58 $\mathrm{nm}$ before and after sonication respectively. This is against particle sizes of sample representing the highest extent of carbamation $(5,14 \% \mathrm{~N})$ which displays values of $230 \mathrm{~nm}$ and $29 \mathrm{~nm}$ before and after sonication respectively. This indicates that there is a tendency for the gum carbamated to be more susceptible to miniaturization by sonication than the control sample due to the presence of the carbamate groups in the molecular structure of the gum. The carbamated groups seem to perform: (i) opening up the gum structure and (ii) enhancing its water affinity. Both functions aggravate the adverse effect of sonication on particle size of the gum.

\section{References}

1. Goyal P., Kumar V. and Sharma P., Cyanoethylation of tamarind karnel powder, starch - starke, 60 (1), 41-47, ISSN 1521379X (2008).

2. El-Siddig K., Gunasena H.P.M., Prasad B.A., Pushpakumara D.K.N.G., Ramana K.V.R., Yijayanand P. and Williams J.T., Tamarind Tamarindus Indica. Southampthon Center

Egypt.J.Chem. Special Issue (2017) for Underutilised Crops. Southampton, ISBN 085-4328599, UK (2006).

3. Kumar C.S. and Bhattacharya S., Tamarind seed: Properties, processing and utilization. Critical Reviews in Food Science and Nutrition, 48 (1), 1-20, ISSN 1549-7852 (2008).

4. Freitas R.A., Martin S., Santos G.L., Valenga F., Buckeridge M.S. and Reicher F., et al., Physicochemical properties of seed xyloglucans from different sources, Carbohydrate Polymers, 60 (4), 507-514, ISSN 0144-8617 (2005).

5. Patel T.R., Morris G.A., Ebringerova A., Vodenicarova M., Velabny V. and Ortega A., et al., Global conformation analysis of irradiated Xyloglucans. Carbohydrate Polymers, 74 (4), 845-851, ISSN 0144-8617 (2008).

6. Wang Q., Ellis P.R., Ross-Murphy S.B. and Burchard W., Solution characteristics of the Xyloglucanextracted from Detarium senegalense Gmelin, Carbohydrate Polymers, 33 (2-3), 115-124, ISSN 0144-8617 (1997).

7. Sims I.M., Gane A.M., Dunstan D., Allan G.C., Boger D.V. and Melton L.D., et al., Rheological properties of xylogucans 
from different plant species, Carbohydrate Polymers, 37 (1), 61-69. ISSN 0144-8617 (1998).

8. Abo-Shosha M.H., Ibrahim, N.A., Allum E.A. and EL-Zairy E.M., Preparation and characterization of polyacrylic acid/karaya gum and polyacrylic acid/tamarind seed gum adducts and utilization in textile printing, Carbohydrate Polymers, 74 (2), 241-249, ISSN 0144-8617 (2008).

9. Tepparin S., Saeobe P., Suesat J. and Chumrum S., Preparation of tamarind - seed Thickener for Pigment printing on cotton, Advanced Materials Research, 233-235, 1388-1391, ISSN 1022-6680 (2011).

10. Ibrahim N.A., Abo Shosha M.H., Allum E.A. and El-Zairy E.M., New thickening agents based on tamarind seed gum and Karaya gum polysaccharides, Carbohydrate Polymers, 81 (2), 402-408, ISSN 0144-8617 (2010).

11. Jacobson R.A., J. Am. Chem. Soc., 60, 17421744 (1938).

12. Segal L. and Eggerton F.V., Text. Res. J. 31, 460-471 (1961).
13. Whistler R.L. and BeMiller J.N., Industrial Gums $3^{\text {rd }}$ Ed., Academic Press Inc., New York, London, Tokyo, P. 2, 194, 215-218 (1993).

14. Hebeish A., Abd El-Thalauth, I., Refai R. and Ragheb A., Starch / Staerke, 41, 293 (1989).

15. Judd B.D. and Wyszecki H.; Colour in Business, Science and Industry $3^{\text {rd }}$ Ed., John Wiley and Sons (1975).

16. The Society of Dyers and Colourists; standard methods for the assessment of colour fastness of textiles, Third Report of the Fastness Tests Coordinating Committee, York shire, England, P. 24, 37, 63 and 71 (1955).

17. Ali Mohammed Shahin A., Ph.D. Thesis, Faculty of Applied Arts, Helwan University (2011).

18. El sayed El Naggar M., M.Sc Thesis, Faculty of Science, Al Azhar University (2008).

19. Abd El - Thalouth I., El - Kashouti M.A. and Hebeish A., Starch/Staerke, 33, 306-310 (1981).
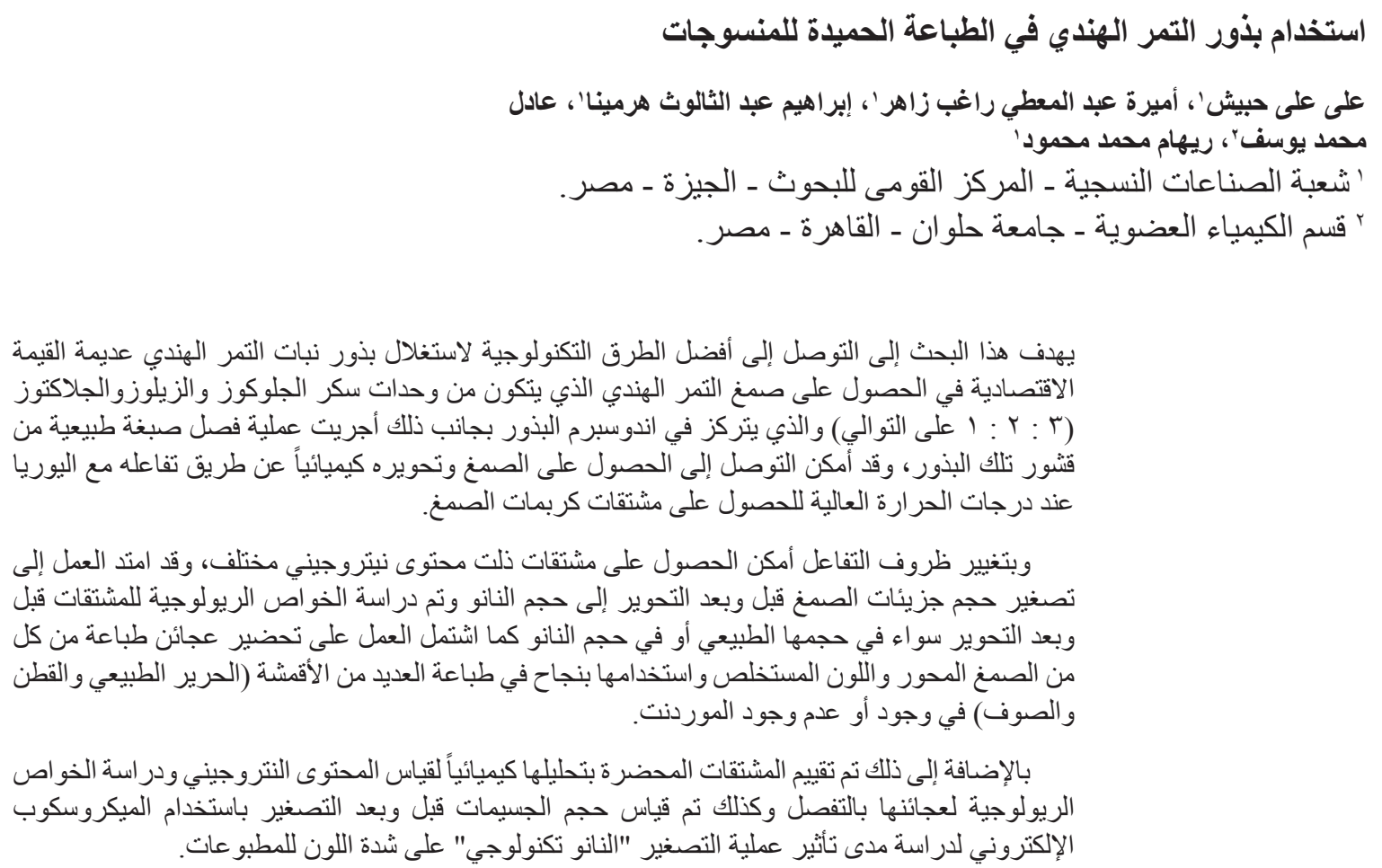